\section{Career management skills: Assessing for learning}

\author{
Ronald G Sultana
}

Euro-Mediterranean Centre for Educational Research, University of Malta, Malta
Australian Journal of Career Development 22(2) 82-90 (C) Australian Council for Educational Research 2013 Reprints and permissions: sagepub.co.uk/journalsPermissions.nav DOI: $10.1177 / 1038416213496759$ acd.sagepub.com

(3SAGE

\begin{abstract}
This paper explores approaches to assessing career learning. A distinction is drawn between formative and summative assessment, in terms of their underpinning philosophy, the learning theories that inform them, and the relative emphasis they place on process and outcome. Both approaches are considered valid. It is however argued that formative assessment is particularly suitable for evaluating career management skills, and that the use of career learning portfolios opens up opportunities for insightful reflection on one's career development, and for career conversations with mentors. The paper concludes by highlighting practical, ethical, and equity issues related to the use of portfolios.
\end{abstract}

\title{
Keywords
}

Career learning assessment, career learning portfolios, career management skills, career learning, career conversations, career development, career education

\section{Introduction}

This paper outlines a number of issues related to the assessment of learning of career management skills (CMS) in education and in employment services. By CMS, we are referring to competences which provide structured ways for individuals and groups to gather, analyze, synthesize, and organize information about oneself and about educational/training pathways and occupations, as well as the skills to make and implement decisions and transitions. Several countries have attempted to develop a formal program or framework for the organization of CMS learning, with some of the best known being the so-called DOTS model (Law, 1999; Law \& Watts, 1977), and the Canadian Blueprint for Life/Work Design - which, as Hooley, Watts, Sultana, and Neary (2012) note, was inspired by the National Career Development Guidelines developed in the US in 1989, and which in turn served as a model for the Australian Blueprint. It is increasingly recognized that in Knowledge-Based Economies, where frequent vertical and horizontal occupational mobility are expected to become more common, citizens of all ages and across the whole lifespan can benefit from developing skills to better manage "protean," "boundaryless" careers (Arthur \& Rousseau, 1996; Hall \& Moss, 1998). In Europe, the European Lifelong Guidance Policy Network
(ELGPN) - made up of representatives from 27 European Union Member States and funded since its establishment in 2007 by the European Commission in order to promote policy development in the area of career guidance (ELGPN, 2010; Watts, Sultana, \& McCarthy, 2010)- has identified CMS as a key focus for its work and is attempting to develop a pan-European CMS framework, which outlines the competences that individuals should have in order to better manage their career and to become protagonists in articulating their life project.

In other publications, I have discussed at some length CMS program rationale, content, and teaching methodologies (Sultana, 2012). I have also pointed out some of the problems with career education initiatives that run the risk of inadvertently exporting structural economic problems onto individuals-a process of "responsibilization" (Ball, 2008) which, for instance, blames unemployment on a person's "lack" of CMS rather than on broader macroeconomic failings beyond the control of citizens (Sultana, 2011). In these papers, I drew on responses that ELGPN members gave to questionnaire surveys regarding the state of career learning in their respective countries, as well as on a series of reviews of career guidance policies across Europe (Sultana, 2004, 2008; Sultana \& Watts, 2006a, 2006b). These responses, 
together with information provided to the author at various network meetings in which I serve as consulting expert and resource person, suggest that while several initiatives are in place promoting different aspects of career education in schools and employment services, very little effort is currently being made to assess actual learning. The lack of attention to assessment of career learning is significant, not least because it may transmit the message that CMS is not an important area within the learning program, with a consequent drop in motivation for it, both on the part of program providers, and of learners.

This paper therefore sets out to unpack some of the central issues concerning the assessment of career learning and is structured around three main concerns. First, the paper focuses on the value of assessment for learning and assessment as learning and considers the range of assessment strategies available, as well as which strategies are suitable in which context and for what purpose. Second, the paper covers in some detail the use of portfolio approaches in assessing career learning, given that portfolios, whether paper-based or in their digital versions, are widely considered to be suitable for assessing CMS learning. Finally, three critical issues concerning the use of portfolios for the assessment of career learning in education and employment service settings will be presented, with a view to enhancing a reflexive stance that is vital if programs are to live up to their ethical, enabling, and equity-enhancing objectives.

\section{Assessing for career learning}

Assessment serves a number of functions in learning including (a) informing learners about their progress, and indicating next steps, (b) informing others (such as parents and employers) about the new or improved competences of an individual, (c) providing credentials that formally signal a competence profile, and (d) encouraging engagement and motivation-here assessment and feedback is most effective when it is timely, specific, personalized, challenging, and constructive (Gardner, 2012; Tovani, 2011).

Given that learning, whether in education/training or employment service settings, entails the use of public or/and private resources (in terms of time, effort, and money), those providing and receiving learning services are often under an obligation to demonstrate outcomes. In many cases, such evidence of learning is provided through formal or informal assessment, which often though not always leads to accreditation. There is a whole range of assessment methods that can be drawn upon, including, but not limited to: self-assessment, peer assessment, formal examinations, synoptic testing, interviews, simulation, practical demonstration of competence, skills samples, projects and assignments, mixed media demonstrations, logs and reflective journals, records of achievement, competence-based transcripts, monitoring of Individual Learning Plans, portfolios, and so on (Banta, Jones, \& Black, 2009). The choice of one or more assessment strategy depends on a number of factors, including the nature of the learning task, the reason for which the assessment is being carried out, the characteristics of the learner (e.g. his or her learning style, age, developmental concerns, life situation), and the context in which learning takes place.

In the case of CMS, the choice of assessment strategies presents specific challenges and issues given that both process and outcomes are important, and because in formal education settings career learning can be-and often is - diffused throughout the curriculum rather than as a stand-alone "subject" (Barnes, 2009a; Sultana, 2012). In an "infusion" approach, it becomes essential that learners are able to identify the CMS elements integrated in a range of subjects and to make links between the career development learning acquired across the curriculum. In some education systems, a "career development coordinator" is tasked with ensuring that students and teachers are aware of the career-related elements across the different curricular areas and with organizing activities that support cross-curricular collaboration. This, for instance, is the case with Austria. Unless such overt curriculum "mapping" takes place, it is easy for CMS to be "so embedded in the classroom activities that neither teachers nor students are aware that something other than content is being conveyed" (Gfroerer, 2000, p. 125). This makes the task of assessing career learning even more challenging, and indeed, focusing on the need to assess these skills helps students, teachers, as well as administrators and parents recognize and value CMS.

A major distinction that is increasingly made in the evaluation of learning is whether assessment is of learning, or for learning. The former considers assessment as the destination of learning (the focus is thus on outcome), while the latter sees assessment as part of learning (assessment is important inasmuch as it supports the learning process). Traditionally, this distinction used to be articulated by differentiating between summative and formative assessment (Harlen \& James, 1997), though in fact, as Taras (2005) points out, all assessment begins with summative assessment (which is a judgment), with formative assessment being summative assessment plus feedback which is used by the learner. The distinction between the two forms of assessment is nevertheless real, in that with summative assessment the goal is to provide a formal profile of where a learner is at in terms of the mastery of a pre-determined knowledge base or competence. Summative assessment often leads to formal credentialing/accreditation and is meant to signal achievement both to the learner and to external parties, including further and higher education institutions and employers, for instance. In most cases, summative assessment shows achievement in relation 
to a comparable group of learners and may be a highstakes exercise in that it can exclude individuals from opportunities to participate in further education and training or employment, for instance.

Formative assessment, on the other hand, is primarily aimed at the learner himself or herself, who is invited to consider his or her progress in learning in relation to his or her own past achievement. Such assessment is usually continuous in nature and scope, open-ended, and leaves the learner in charge of the learning process (Bennetta, 2011; Clark, 2012). It is also linked to the notion of assessment as learning (Earl, 2003), i.e. critical reflection on one's own learning progress in order to plan next steps, with the help of mentors and tutors. Such learning to learn strategies can be strengthened through the use of personal learning plans, for instance. Some assessment strategies are more amenable to summative assessment (e.g. examinations), while others are more likely to be used when the assessment goal is formative (e.g. portfolios, reflective diaries).

One can represent summative and formative assessment strategies as being in tension with each other (with the former being underpinned by behaviorist learning theories, for instance, and the latter by constructivist ones). In this paper, however, it is suggested that the choice of both assessment form and strategy depends on function: i.e. the mix and match from equally legitimate alternatives depends on what is being assessed, and why. The concern therefore is around the choice of assessment modalities that are "fit for purpose." It is however also proposed that when it comes to career learning, formative modes of assessment are likely to be more suitable and to open up more opportunities for powerful learning, whether with adolescents, youths, or adults. This should not exclude the judicious use of summative forms of assessment if and when the situation warrants it. A concern here is that many learners, especially in examinationoriented education systems, only take seriously that which is credited, examined, or formally assessed.

\section{Career learning and formative assessment}

There are strong arguments favoring the use of formative types of assessment in career learning. The latter is arguably a different kind of area of knowledge than "mainstream" curricular subjects (Barnes, Bassot and Chant, 2011), which tend to be more tightly "framed" and "bounded" (Bernstein, 1973) in terms of disciplinary content. A CMS program is typically multi-disciplinary, drawing its knowledge and skills base from such areas as personal psychology, economics, labor studies, sociology, ethics, and so on. It is also often "linked to wider processes and systems for supporting and promoting personal development" (Barnes, 2009b, p. 6). CMS learning is therefore difficult to assess by any means, let alone by summative assessment strategies which, by definition, are best suited to test mastery of a pre-specified and tightly bounded knowledge base.

Furthermore, many career learning programs, whether in education or employment service settings, are built on interactive and constructivist pedagogies. Constructivism emphasizes that learning takes place gradually and incrementally, with students building upon knowledge they already have (Matthews, 2003; Richardson, 2003). Constructivism also considers learning as an interactive process involving a variety of players, rather than an activity carried out by a single person (the teacher or instructor). This has implications for assessment, emphasizing the value of continuous and formative assessment strategies which connect with the dynamic process of meaning-making over time and in context.

An additional consideration concerns the fact that in education settings, in particular, career learning typically gives more importance to process (including "meta" skills and knowledge, such as learning how to make decisions and learning how to learn) than to product (reaching the "decision" or the "learning goal"). In a CMS program, the focus is on supporting a personalized learning journey through a diagnostic and formative process, with formative assessment supplying the most suitable strategies in providing such support. In education settings, therefore, the focus is not on establishing whether a student has "passed" or "failed," but what progress has been achieved along the journey of career learning. Within employment service settings, CMS provision, by definition, tends to be tightly linked to the pragmatic consideration of getting unemployed persons into jobs, and in some cases, career learning is recorded and assessed in ways that facilitate recruitment. In such cases, assessment can become more goaloriented and more summative in nature.

In the next section of this paper, we will look in more detail at one of the more popular formative assessment tools used in career learning programs, i.e. portfolios. Before we do that, however, we will provide details of a more summative, behavioristically oriented approach to assessing CMS. Such an approach tends to be associated with CMS competence-based programs, where learning outcomes are set out in some detail, and different levels of competence mastery are also specified. It should be noted that both the Canadian and Australian CMS Blueprint models establish a series of specific and observable learning outcomes, rendering each component of the CMS program testable in summative ways (Hooley et al., 2012).

A key advantage with competence-based CMS programs is that they clearly specify what needs to be learnt, thus helping to demystify and pin down this "slippery" area of multi-disciplinary knowledge. A potential disadvantage with such "mastery learning" approaches is that the breaking down of complex 
tasks into component parts makes assessment of learning fragmented, over-bureaucratic, and ultimately meaningless (Sultana, 2009). "CompetenceBased Transcripts" represent one assessment tool that attempts to exploit the advantages - and avoid the pitfalls - just mentioned by drawing on both summative and formative assessment strategies. They strive for a greater degree of validity, reliability, and consistency across a range of settings than do formative assessment strategies, with competence in specific CMS being determined "by assessment against a performance standard that is supported not only by skill attainment, but knowledge and understanding in a variety of contexts or applications" ensuring that underlying knowledge is not sacrificed to performance outcomes (Gfroerer, 2000, p. 123). Box 1 provides an example of a competence-based approach to one of the central areas in a CMS program, articulated in such a way as to facilitate the development of a Competence-Based Transcript.

\section{Career learning portfolios}

Portfolios are possibly the preferred assessment tool used in those countries that have integrated CMS in or through their school curricula, whether at compulsory or higher education levels. Respondents to the ELGPN surveys referred to earlier indicated that they are used in education settings in Austria, Croatia, Denmark, Finland, France, Germany, Ireland, Luxembourg, and the UK and are being introduced in Malta and in a number of other countries. There are few countries that report using portfolios in employment service settings - other than, as in Belgium for instance, as a electronic platform for displaying job-seekers' competence profile. The potential and opportunity for enhancing employment service use of portfolios for career learning is certainly there, given the widespread use of Personal Action Planning, an exercise which can become bureaucratic rather than meaningful unless sustained through the keeping of a reflective record. In this section, we will consider different types of portfolios, and their value in assessing career learning. Our focus is not as much on the valid practitioner's concern of how to construct a portfolio, as on whether portfolios are a suitable tool to implement an assessment policy in career learning. ${ }^{1}$

The term Portfolio comes from the Latin portare (to carry/movable) and folium (document/artifact), and as we shall note, such "movable artifacts" can

Box I. Example of a competence-based approach to decision making and problem solving.

\section{Decision making and problem solving}

Proficiency in decision making and problem solving means that the student will make developmentally appropriate decisions and will use problem-solving strategies to investigate information and gain understanding in a variety of settings.

The student shall submit evidence to demonstrate to the assessor(s) that the following standard has been met in its entirety. This evidence should be gathered from more than two courses of veritable experiences to show consistent skill. The student's proficiency level in each competency area will be evaluated by: (I) assessing how closely the evidence submitted meets this written standard, (2) the Assessor(s) Professional Judgment, and (3) comparison of the student's evidence with Exemplar work that illustrates 'Proficient' in each competency area.

Performance Standard: The student will demonstrate the ability to:

\section{Grade 9}

Outline issues involved in a situation, problem, or challenge

Determine, collect, and organize information needed to formulate a solution

Identify solution options available

Develop and test strategies or options that might work

Grade 10 (in addition to above)

Provide examples of the strategies or options tested or tried

Compare and analyze the pros and cons of identified strategies or options

Through Teamwork, arrive at a decision or determine a solution that is well suited to the task

Grade II and 12 (in addition to above)

Independently arrive at a decision or determine a solution that is well suited to the task

Communicate, in a clear format, how the solution was formed

Justify or describe how and why a particular solution option was chosen

Guidance Notes for Assessors:

The evidence submitted for this competency must include an example of problem solving in mathematics and an example encountered in a real-life situation, such as work-based learning, school-based learning, job skills practice, or other career development decisions. The mathematics work submitted as evidence must demonstrate proficiency in computation as well as problem-solving skills to meet this standard. The mathematics work may occur in any setting, not necessarily a mathematics class, and the mathematics example may occur in the context of the real-life setting.

Time frames for decision making appropriate for the task within an assignment or activity will be established in the learning environment (the class, task group, work experience, etc).

A portfolio of evidence may be used to demonstrate this process.

Source: Gfroerer, 2000. 
be paper-based or digital (e-portfolios). As several authors note (Chetcuti \& Grima, 2001; see also Johnson, Mims-Cox, \& Doyle-Nichols, 2009), there are different types of portfolios, including developmental and reflective - with the focus placed on learning - and representational-where the focus is on "showcasing" achievements. The different types of portfolios, which are visually represented in Figure 1, are not mutually exclusive and can be merged to achieve different learning, personal or work-related outcomes. In this paper, we are mainly interested in those portfolios whose focus is reflection and learning, and which track personal development-what we will refer to as "career learning

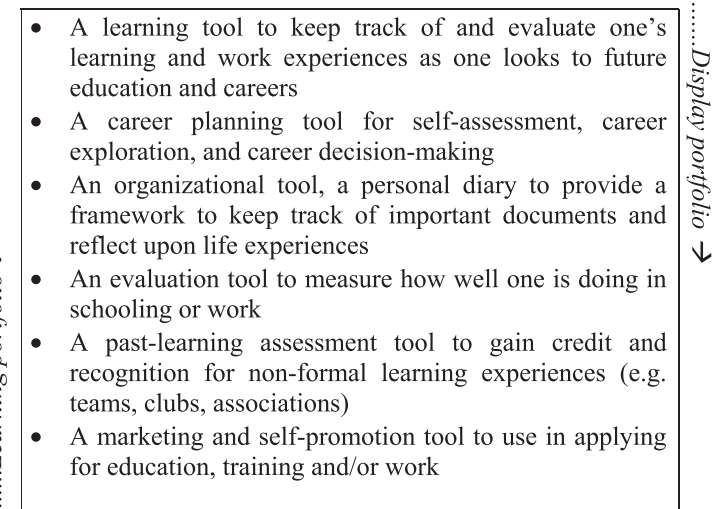

Figure I. Types and uses of career portfolios. portfolios" (CLPs). We will therefore not refer much at all to "Career Portfolios," which are a visual representation of a person's abilities, skills, knowledge, and qualities, in a bid to represent-and provide evidence of - one's potential by demonstrating what has been accomplished in the past, often to prospective employers. This does not of course mean that such portfolios are not of interest to career guidance specialists - not least because they have a role to play in an area that is of increasing interest to the field, namely the accreditation of prior experiential learning (APEL).

Typically, CLPs encourage learners to focus on key CMS, which are organized around overarching categories such as personal attributes related to career goals, career beliefs, decision making, transition issues, gathering and making sense of information related to further education and training as well as career pathways, developing a network of people who can assist in achieving career goals, and so on. Box 2 reproduces the categories for career learning program development that are suggested by the USbased National Career Development Association (NCDA), but as noted earlier, there are several other CMS frameworks available, including the Canadian and Australian Blueprints.

Portfolio keeping involves collecting, selecting, reflecting, projecting, and celebrating. The Portfolio thus becomes the site for documenting schoolto-work (in education settings) and unemploymentto-training/work or work-to-work (in employment service settings) learning, and one's reflections on that learning. The main aim of this documentation

Box 2. NCDA National Career Development Guidelines.

NCDG standards developed by the National Career Development Association (NCDA, USA) provide learner outcome criteria for designing career learning programs. Domains, goals, and indicators organize the NCDG framework. The three domains of Personal Social Development (PS), Educational Achievement and Lifelong Learning (ED), and Career Management (CM) describe content. Under each domain are goals ( $\mathrm{II}$ in all) that define broad areas of career development competency.

Personal and Social Development Domain

- GOAL PSI Develop understanding of self to build and maintain a positive self-concept

- GOAL PS2 Develop positive interpersonal skills including respect for diversity

- GOAL PS3 Integrate growth and change into your career development

- GOAL PS4 Balance personal, leisure, community, learner, family, and work roles

Educational Achievement and Lifelong Learning Domain

- GOAL EDI Attain educational achievement and performance levels needed to reach your personal and career goals

- GOAL ED2 Participate in ongoing, lifelong learning experiences to enhance your ability to function effectively in a diverse and changing economy

Career Management Domain

- GOAL CMI Create and manage a career plan that meets your career goals

- GOAL CM2 Use a process of decision making as one component of career development

- GOAL CM3 Use accurate, current, and unbiased career information during career planning and management

- GOAL CM4 Master academic, occupational, and general employability skills in order to obtain, create, maintain, and/or advance your employment

- GOAL CM5 Integrate changing employment trends, societal needs, and economic conditions into your career plans

Under each goal in the framework are indicators of mastery that highlight the knowledge and skills needed to achieve that goal. Each indicator is presented in three learning stages derived from Bloom's Taxonomy: knowledge acquisition, application, and reflection. The stages describe learning competency. They are not tied to an individual's age or level of education. 
is to support purposeful learning, which is the basis for planning of further action. All sorts of learning can be documented and celebrated, including formal learning that takes place in and across the education and training curriculum (at whatever level), and in any setting (such as learning from work experience, experience in part-time and holiday jobs, in full-time employment, and so on). The power of the CLP comes from the process requiring learners to identify and reflect upon what motivates and satisfies them, a process that involves the documenting of one's interests, skills, values, needs, goals and strategies, and a reflection upon them (Wright, 2001).

The kinds of practices we encourage with portfolios reflect our learning theories, for as we have already seen, the way we approach learning conditions our choice from among assessment strategies. If our CMS programs are driven by behaviorist and positivist notions of teaching and learning (i.e. they assume that meaning is constant across users, contexts, and purposes), then the portfolio is likely to be a receptacle for examples of student work, which are then used to infer what and how much learning has occurred. Such a selection of items will tend to reflect external standards and interests. If, on the other hand, a CMS program is inspired by constructivist approaches, then the portfolio is more likely to stress the selection of items that reflect learning from the student's perspective. In this case, the whole point of a portfolio is to provide a learning environment in which the learner constructs meaning, and the portfolio becomes a record of the processes associated with learning itself (Barrett \& Wilkinson, 2004).

CLPs based on such constructivist approaches are often commended for use in career learning because they provide "a powerful environment for planning, refection and review, recording evidence and celebrating achievement" (Barnes, 2009b, p. 6). They are considered to be "useful for focusing on elements of career learning that are difficult to accredit such as curiosity, persistence, flexibility, optimism and risktaking" (Barnes, 2009b, p. 6). In education settings where, as noted earlier, career learning is diffused throughout the curriculum, portfolios help make CMS learning more visible to students, who can consequently make the link between different inputs by different teachers in purposeful and self-reflective ways. The portfolio becomes a useful tool to construct meaning on the basis of disparate curricular material presented in different subject areas. From a lifelong perspective, portfolios can serve to link various career services and resources throughout the career path of an individual.

CLPs are best seen as another manifestation of the "constructivist turn" in teaching and learning, as well as in career development theory (Savickas, 1997). As such, CLPs are often used in conjunction with Individual Learning Planning (in education settings) and Personal Action Planning (in employment service settings), since all are underpinned by compatible and similar cognitive and pedagogical/andragogical approaches. The overall focus is "deep learning," which is characterized by involving reflection, and by being developmental, integrative, self-directive, and lifelong (Barrett \& Wilkinson, 2004). Such deep learning is facilitated and enhanced when learners have the opportunity to plan and assess their own learning - a process that is referred to as "metacognition."

CLPs capture both process and product - the reflection on one's efforts to learn as well as the learning outcomes achieved. In relation to career learning, and particularly in education settings, CLPs are a means to an end, and not an end in themselves - which tends to be the case with career portfolios, where display of evidence of achievement is what matters most. CLPs are therefore a good example of a formative assessment mode, and since they provide a multidimensional picture of a student's learning over time, are an excellent basis for meaningful "career conversations" (Mittendorff, Jochems, Meijers, \& den Brok, 2008). Such planned conferencing sessions, facilitated by trained career workers, are vital in helping learners talk about the contents of the portfolio, to attribute meaning to them, to increase self-efficacy, and to negotiate an action plan, including new learning goals.

Digital or e-portfolios, which are increasingly popular, add further dimensions to the potential of CLPs. The use of an internet-based platform, managed by the user, expands the display options of a portfolio to include electronic files, images, multimedia, blog entries, and hyperlinks besides text (Barrett, 2008; Kilbane \& Milman, 2002; Reardon \& Hartley, 2007). The infusion of technology in the process also adds such dimensions as archiving, linking/thinking, storytelling, planning, and publishing (Barrett \& Wilkinson, 2004), some of which have a direct impact on learning. Hyperlinking, for instance, leads to metacognition, which in turn facilitates deeper learning. E-portfolios widen the scope of the career conversations that are at the heart of CMS learning, given that their owners can determine levels of access to the material they include. CLPs operating on a web platform can thus become a powerful tool for constructivist coaching not only with peers, teachers, and career guidance specialists, but also parents and employers, all of whom may be given access rights to the site in order to contribute to the learning and feedback process. For reasons such as these, there is some evidence that the use of digital portfolios leads to better learning outcomes than paper-based portfolios in the same setting (van Wesel \& Prop, 2008).

Over and above the potential of portfolios as tools for assessing the learning of CMS, it bears pointing out that CLPs can address a range of career guidancerelated policy concerns. CLPs, for instance, can enhance access to career guidance services in that 
they are closely linked to broader learning goals, and hence potentially seen by students in education settings to be more relevant to their immediate life concerns. In other words, students who might not be willing to use, or might not even be aware of, oneto-one or group career guidance services, might engage more willingly with career learning through a CLP. Learners using CLPs can benefit from feedback from teachers, from employment officers, and from employers networked by the public employment services (PES), thus facilitating cross-sectoral collaboration. Indeed, the CLP can be seen as a tool for lifelong career development as individuals make transitions from education to employment, back to training, and into new jobs, with the support of staff from public or private employment services, when needed. The French e-portfolio PEC (Portefeuille d'Expériences et de Compétences) is an example of this. Finally, the strongly constructivist and learning-oriented, reflexive approach to career thinking and career development has great potential in improving the quality of career guidance services.

\section{Issues and problems with portfolios}

Despite the many benefits and advantages of CLPs, and their potential in furthering career learning goals, it is important to also critically reflect on their use and to highlight some concerns. Three such concerns are outlined below, the consideration of which has implications for policy.

Experience in the use of CLPs suggests that the career conversations that are of central importance to the whole process are time- and resource-consuming and difficult to keep up given that they often (though not always necessarily) require one-to-one or small group sessions. Many career workers and CMS teachers have not been trained to make good use of portfolio material and to work with learners in a way that helps individuals develop a career identity through the construction of a narrative within a career conversation. Furthermore, most schools do not have the "space" yet-whether institutionally or culturally-to organize career conversations (cf. Winters et al., 2013). When individuals are not mentored and given adequate feedback, they tend to lose interest in, and enthusiasm for, the updating and maintaining of their CLP, and the formative assessment and learning enhancing role of the whole exercise is jeopardized. Mittendorff et al. (2008, p. 77) note that when this happens, "students will react in the same manner as they react to the curriculum they do not see as relevant: they will try to achieve maximum results with a minimal effort."

Mittendorff et al.'s (2008) analysis of three cases studies where CLPs were used in Dutch vocational schools is instructive in showing up the gap between intention and reality. The authors found that the majority of the teachers and counselors perceived portfolios and personal development plans as instruments to collect evidence on student development, to stimulate self-responsibility or self-direction of students, and to support students in reflecting on identity and future ambitions; and to set up learning goals to achieve this. However, portfolios and personal development plans were often used instrumentally but not to support career dialogues; the instruments were used by students mainly to collect information about themselves, but information was not used in conversations between teachers and students to stimulate reflection. If instruments were not used in a context of dialogue, students perceived them as irrelevant and refrained from using them to reflect on identity or future plans. If teachers used portfolios and personal development plans as a basis for a career dialogue, students were more likely to appreciate the instruments and to reflect on their identity and future ambitions.

Some authors have highlighted the value of CLPs for vulnerable groups of students and youths, such as those from depressed economic backgrounds, low achievers, and persons with disability (Koch \& Rumrill, 1999). Mittendorff et al. (2008) also claim, for instance, that many Vocational, Education and Training (VET) youngsters in several Western European countries - who are often low achieving and have learning difficulties - face problems around personal identity development and making choices for the future. Such at risk youths often find it difficult to learn in a self-directed manner and experience less support in constructing their lives and careers, so that career guidance programs, including the use of portfolios, can provide support in developing these skills.

Others, however, have pointed out that the "habitus," frame of mind, and dispositions required by CLPs and Individual Education Planning are alien to learners from working class backgrounds, who are less likely to think of work as a "career," who tend not to be as individualistic, forward-planning and long-term in orientation (as assumed by middleclass-oriented career development theories), and who have their own strategic and more collectivist ways of managing the transition to work, in relation to which CLPs are neither applicable nor suitable (Collin, 2011a). As a genre, the portfolio "requires students to individualize themselves," as well as "to endorse [...] a middle-class ideology of self-cultivation and self-promotion" (Collin, 2011b, p. 329). The very form of the portfolio, i.e. the way it is constructed, worded, and invested with meaning, requires students to "take on particular identities, contract specific kinds of relationships, connect certain things in certain ways, and construe particular things as having particular kinds of significance" (Collin, 2011b, p. 339). Similar views and critiques have been made of Individual Learning Plans (Hamilton, 2009). To the class dimension one can add gender considerations, in that the dis/playful nature of portfolios, together 
with their focus on literacy and organization of identity-related material, might make them more consonant with feminine learning styles, at least in some cultures.

A further concern has been expressed in relation to the potential of CLPs of becoming yet another instance reinforcing the culture of surveillance and record keeping that can subvert educational principles and goals-particularly when such documents are used to mediate the transition from school to work and end up in employers' hands. Portfolios thus raise a host of ethical issues and can be subject to legal challenge when used for a purpose other than that for which they were intended, or when there are suspicions that they will intrude on citizens' right to privacy and render them vulnerable. In France, for instance, the plans by the State to introduce webbased portfolios detailing the competences of each individual person, as well as his or her experience in a range of associations outside schools, has led to a spirited internet-based campaign of resistance, comparing this initiative to the "livret ouvrier" (or "worker's schedule book") that was used in the 19th century to track, surveil and control workers. $^{2}$

\section{Conclusion}

Career learning is featuring increasingly high on the agenda of education and employment services, with transformations in career pathways and trajectories - rendered even more complex and insecure by the international economic crisis and recession-leading many to argue that citizens are entitled to receive support in the difficult task of constructing life projects. While several countries have given attention to developing career education programs and to fostering CMS in young people and adults alike, few have focused on developing appropriate strategies for the assessment of career learning. This paper has highlighted the need to develop such strategies and has singled out CLPs as a promising tool that, when accompanied by career conversations with skilful mentors, has great potential in extending and deepening citizens' critical understanding of the world of work, and their multi-faceted relationship to it.

\section{Acknowledgements}

This article draws on a concept note commissioned by the European Lifelong Guidance Policy Network. Thanks are due to the ELGPN members for their feedback on earlier drafts and for permission to publish this paper. Needless to say, I remain responsible for the views expressed.

\section{Declaration of conflicting interests}

None declared.

\section{Funding}

This research received no specific grant from any funding agency in the public, commercial, or not-for-profit sectors.

\section{Notes}

1. Examples of career portfolios of all types, ranging from the most basic to the more sophisticated are easily found on the internet. The following links might prove useful to practitioners: A self-managed career learning portfolio: http://www.edu.gov.mb.ca/k12/docs/support/c_portfolio/-A guidebook for building a career portfolio, aimed to support career staff in their work with students: http://curriculumorg/storage/108/1278484153portfolios. pdf - A guide to designing a career learning module in a higher education setting, with examples of assessment: http://www2.warwick.ac.uk/study/cll/about/cllteam/ pmccash/ccms_ career_studies_example_08_11.pdf-A website dedicated to the development and use of digital portfolios: http://electronicportfolios.org/—An example of a school-based career development program, and the use of a portfolio to integrate learning: http://wwwtrinity.wa.edu.au/intranet/subjects/careers/Trinity CareersBook.pdf

2. See http://www.slideshare.net/franckdda/diaporamalivretpersonneldecompetences

\section{References}

M. B. Arthur, \& D. M. Rousseau, (Eds.) (1996). The boundaryless career: A new employment principle for a new organizational era. Oxford, UK: Oxford University Press.

Ball, S. J. (2008). The education debate. Policy and politics in the twenty-first century. Bristol, UK: Policy Press.

Banta, T. W., Jones, E. A., \& Black, K. E. (2009). Designing effective assessment: Principles and profiles of good practice. San Francisco, CA: Jossey-Bass.

Barnes, A. (2009a). Assessment for career learning and development: Now or never? Career Education and Guidance, February, 2-7.

Barnes, A. (2009b). Careers education units and qualifications for young people. CEIAG Briefings. Connexions: $\mathrm{H}$.

Barnes, A., Bassot, B., \& Chant, A. (2011). An introduction to career learning and development 9-11. London and New York: Routledge.

Barrett, H. (2008). Researching electronic portfolios and learner engagement. White Paper, The Reflect Initiative. Retrieved from http://electronicportfolios.org/

Barrett, H. C., \& Wilkerson, J. (2004). Conflicting paradigms in electronic portfolio approaches: Choosing an electronic portfolio strategy that matches your conceptual framework. Retrieved from http://electronicportfolios.com/systems/paradigms.html

Bennetta, R. E. (2011). Formative assessment: A critical review. Assessment in Education: Principles, Policy \& Practice, 18, 5-25.

Bernstein, B. (1973). Class, codes and control: Volume 1. London, UK: Routledge \& Kegan Paul.

Chetcuti, D., \& Grima, G. (2001). Portfolio assessment. Malta: National Curriculum Council.

Clark, I. (2012). Formative assessment: Assessment is for self-regulated learning. Educational Psychology Review, 24, 205-249. 
Collin, R. (2011a). Dress rehearsal: A Bourdieusian analysis of body work in career portfolio programs. British Journal of Sociology of Education, 32, 785-804.

Collin, R. (2011b). Lives on file: A critical assessment of the career portfolio genre. Discourse: Studies in the Cultural Politics of Education, 32, 329-342.

Earl, L. M. (2003). Assessment as learning: Using classroom assessment to maximize student learning. California, CA: Corwin Press.

ELGPN. (2010). Lifelong guidance policies: Work in progress - A report of the work of the European Lifelong Guidance Policy Network 2008-2010. Jyväskylä, Finland: University of Jyväskylä.

Gardner, J. R. (2012). Assessment and learning (2nd ed.). Thousand Oaks, CA: Sage Publishers.

Gfroerer, M. (2000). Assessment: Career guidance on the cutting edge of competency-based assessment. Journal of Career Development, 27, 119-131.

Hall, D. T., \& Moss, J. E. (1998). The new protean career contract: Helping organizations and employees adapt. Organizational Dynamics, 26, 22-37.

Hamilton, M. (2009). Putting words in their mouths: The alignment of identities with system goals through the use of Individual Learning Plans. British Educational Research Journal, 35, 221-242.

Harlen, W., \& James, M. (1997). Assessment and learning: Differences and relationships between formative and summative assessment. Assessment in Education: Principles, Policy \& Practice, 4, 365-379.

Hooley, T., Watts, A. G., Sultana, R. G., \& Neary, S. (2012). The 'Blueprint' framework for career management skills: A critical exploration. British Journal of Guidance and Counselling, 41, 117-131.

Johnson, R. S., Mims-Cox, J. S., \& Doyle-Nichols, A. (2009). Developing portfolios in education: A guide to reflection, inquiry, and assessment. Thousand Oaks, CA: Sage.

Kilbane, C. R., \& Milman, N. B. (2002). The digital teaching portfolio handbook: A how-to guide for educators. Boston, MA: Allyn \& Bacon.

Koch, L., \& Rumrill, P. (1999). The career portfolio as a job placement and retention tool for people with disabilities. Journal of Vocational Rehabilitation, 13, 141-142.

Law, B. (1999). Career learning space: New DOTS thinking for careers education. British Journal of Guidance and Counselling, 27, 35-54.

Law, B., \& Watts, A. G. (1977). Schools, careers and community. London, UK: Church Information Office.

Matthews, W. J. (2003). Constructivism in the classroom: Epistemology, history, and empirical evidence. Teacher Education Quarterly, 30, 51-64.

Mittendorff, K., Jochems, W., Meijers, F., \& den Brok, P. (2008). Differences and similarities in the use of the portfolio and personal development plan for career guidance in various vocational schools in The Netherlands. Journal of Vocational Education \& Training, 60, 75-91.
Reardon, R. C., \& Hartley, S. L. (2007). Program evaluation of e-portfolios. New Directions for Student Services, 119, 83-97.

Richardson, V. (2003). Constructivist pedagogy. Teachers College Record, 105, 1623-1640.

Savickas, M. L. (1997). Constructivist career counseling: Models and methods. Advances in Personal Construct Psychology, 4, 149-182.

Sultana, R. G. (2004). Guidance policies in the learning society: Trends, challenges and responses across Europe. Thessaloniki: CEDEFOP.

Sultana, R. G. (2008). From policy to practice: A systemic change to lifelong guidance in Europe. Thessaloniki, Greece: CEDEFOP.

Sultana, R. G. (2009). Competence and competence frameworks in career guidance: Complex and contested concepts. International Journal for Educational and Vocational Guidance, 9, 15-30.

Sultana, R. G. (2011). Lifelong guidance, citizen rights, and the state: Reclaiming the social contract. British Journal of Guidance and Counselling, 39, 179-186.

Sultana, R. G. (2012). Career management skills in Europe: A critical review. Journal of Education and Work, 25, 225-248.

Sultana, R. G., \& Watts, A. G. (2006a). Career guidance in Europe's Public Employment Services: Trends and challenges. Brussels, Belgium: DG Employment, Social Affairs and Equal Opportunities.

Sultana, R. G., \& Watts, A. G. (2006b). Career guidance in Public Employment Services across Europe. International Journal for Educational and Vocational Guidance, 6(1): 29-46.

Taras, M. (2005). Assessment - summative and formative some theoretical reflections. British Journal of Educational Studies, 53, 466-578.

Tovani, C. (2011). So what do they really know? Assessment that informs teaching and learning. Portland, OR: Stenhouse Publishers.

Van Wesel, M., \& Prop, A. (2008). The influence of portfolio media on student perceptions and learning outcomes. Paper presented at Student Mobility and ICT: Can ELearning overcome barriers of life-long learning? 19-20 Nov 2008, Maastricht, The Netherlands. Retrieved from http://www.personeel.unimaas.nl/maarten.wesel/ Documenten/The $\% 20$ influence $\% 20$ of $\% 20$ portfolio $\%$ 20 media $\% 20$ on $\% 20$ student $\%$ 20perceptions $\% 20$ and $\%$ 20learning $\% 20$ outcomes.PDF

Watts, A. G., Sultana, R. G., \& McCarthy, J. (2010). The involvement of the European Union in career guidance policy and practice: A brief history. International Journal for Educational and Vocational Guidance, 10, 89-107.

Winters, A., Meijers, F., Harlaar, M., Strik, A., Kuijpers, M., \& Baert, H. (2013). The narrative quality of career conversations in vocational education. Journal of Constructivist Psychology, 26, 115-126.

Wright, W. A. (2001). The Dalhousie career portfolio program: A multi-faceted approach to transition to work. Quality in Higher Education, 7, 149-159. 